\title{
INFLUENCE OF COOLING RATE ON THE STRENGTH OF THE RIMS OF RAILWAY WHEEL
}

\section{O. Vakulenko}

UDC $669017: 621.78 \cdot 539.4: 621.771 .29$

\begin{abstract}
It is shown that the intense cooling (with rates of $2-9^{\circ} \mathrm{C} / \mathrm{sec}$ ) of wheel rims after their hot rolling in a rolling mill increases the yield limit and the ultimate strength of the metal. It is also established that, in the absence of supersaturation of the solid solution with carbon atoms in the course of this kind of cooling, the mechanical properties of carbon steel are determined solely by the internal stresses caused by the phase hardening of ferrite in pearlite and the state of ferrite-cementite boundaries.
\end{abstract}

Keywords: wheel steel, cooling rate, pearlite, ferrite, strength, dislocation

In the process of intense cooling of rims of the railway wheels subjected to thermomechanical treatment, the cooling rates at different distances from the rolling surface vary within the range $2-9^{\circ} \mathrm{C} / \mathrm{sec}$, which corresponds to the zone of structural transformations in steels according to the diffusion mechanism. Under these conditions, the temperature of the onset of transformation of austenite into pearlite is shifted by $40-50^{\circ} \mathrm{C}$ [1]. The changes in the temperature range of the onset of pearlite transformation are reflected in the regularities of structure formation in carbon steels.

However, it was shown that, for the indicated range of cooling rates, the ratio of the structural components (volume fractions of the structurally free ferrite and pearlitic colonies) remains practically invariable, although the yield limit and ultimate strength of steel may become 20-30\% higher [1]. In other words, the changes in the mechanical characteristics of steel are probably caused by the other specific features of its structure.

The aim of the present work is to analyze the influence of cooling rate on the structural morphology and the strength of steel in wheel rims after hot rolling in a rolling mill.

\section{Material and Procedure}

The specimens in the form of plates $3 \mathrm{~mm}$ in thickness were cut out from different zones of the wheel rim of 2 steel $(0.58 \% \mathrm{C}, 0.65 \mathrm{Si}, 0.45 \mathrm{Mn}, 0.0029 \mathrm{~S}, 0.014 \mathrm{P}$, and $0.11 \% \mathrm{Cr})$ after hot rolling of the workpiece in a railway-wheel rolling mill. The mechanical characteristics of steel (the yield limit $\sigma_{0.2}$ and the ultimate strength $\sigma_{\mathrm{u}}$ ) were determined under tension at a strain rate of $10^{-3} \mathrm{sec}^{-1}$. The morphology, volume fractions of the phase components, and their size characteristics were found by the methods of quantitative metallography [2].

\section{Results and Discussion}

It was shown that, as in [1], the ratio of the volume fractions of pearlite and structurally free ferrite after intense cooling within the investigated range of cooling rates $(V)$ is practically invariable. The strength charac-

Lazaryan Dnipropetrovs'k National University of Railway Transport, Dnipropetrovs 'k, Ukraine; e-mail: dnuzt_texmat@ukr.net.

Translated from Fizyko-Khimichna Mekhanika Materialiv, Vol.51, No.6, pp.80-82, November-December, 2015. Original article submitted May 27, 2015. 


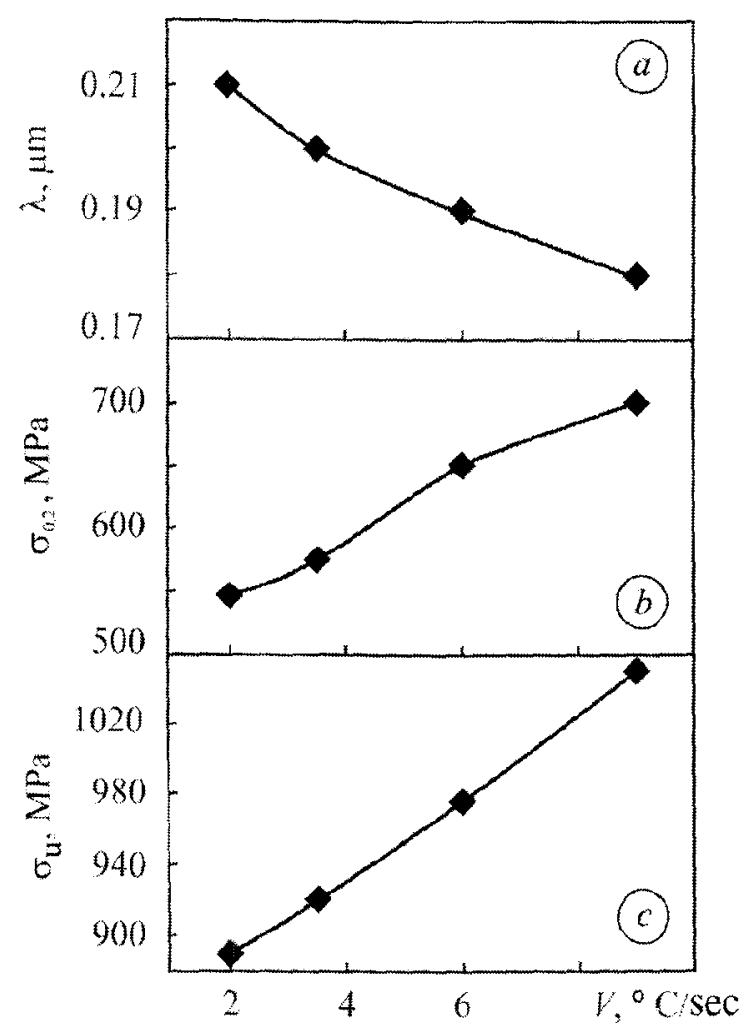

Fig. 1. Dependences of the interlamellar distance in pearlite (a), yield limit (b), and ultimate strength (c) on the cooling rate of the metal of the wheel rim.

teristics depend on the range of particle dimensions of the pearlitic structure. We revealed (Fig. 1) the inversely proportional dependence of the mechanical characteristics of steel on the interlamellar distance in pearlite $(\lambda)$. The analysis of the presented dependences shows that, as the cooling rate increases from 2 to $9^{\circ} \mathrm{C} / \mathrm{sec}$, the values of $\sigma_{0.2}$ and $\sigma_{u}$ become higher by $\sim 160 \mathrm{MPa}$.

It is known [3] that, depending on the size of a structural element, the yield limit of carbon steel is determined by the length of the free path of dislocations. As a rule, this length coincides with the size of ferrite grains in low-carbon steels with ferritic structure. At the same time, for pearlitic structures, the picture is somewhat different. This is explained by the fact that the length of dislocation free path $(\Delta)$ in the course of propagation of plastic deformation in pearlite exceeds the thickness of ferritic interlayer. The investigations of stable slip bands in the ferritic interlayers of pearlitic colonies showed that $\Delta=4.75 \lambda$, i.e., this length is indeed much higher than the thickness of ferritic interlayer in pearlite [3].

The obtained dependences of the strength characteristics of wheel steel on the length of dislocation free path (Fig. 2) obey the following equation of the Hall-Petch type [4]:

$$
\sigma_{0.2} ; \quad \sigma_{\mathrm{u}}=\sigma_{i}+k_{y} \Delta^{-0.5}
$$

where $\sigma_{i}$ are the friction stresses in the crystal lattice of ferrite in the pearlitic colony and $k_{y}$ is an angular coefficient. These parameters depend on the state of solid solution (the concentration of carbon atoms in solid 


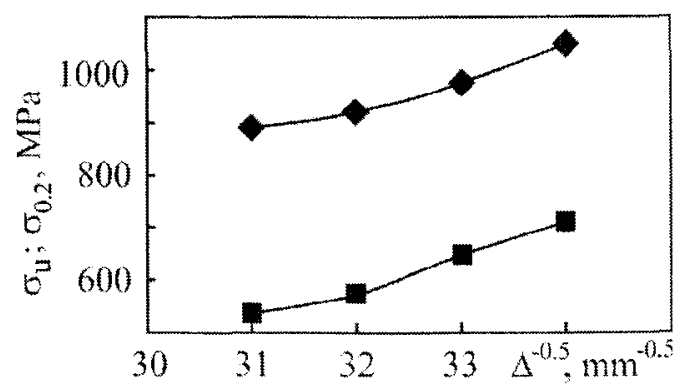

Fig. 2. Influence of the length of dislocation free path in the ferritic interlayer of a pearlitic colony on the yield limit ( $\mathbf{\square})$ and ultimate strength $(\bullet)$ of wheel steel for different cooling rates.

solution) and the interfaces. According to the obtained results (Fig. 2), we find

$$
k_{y} \approx 32 \mathrm{MPa} \cdot \mathrm{mm}^{0.5} \text { and } \sigma_{i} \approx 100 \mathrm{MPa}
$$

For most carbon steels with ferritic-pearlitic structure, $\sigma_{i} \approx 70-90 \mathrm{MPa}[3,5,6]$. Therefore, the obtained value $\sigma_{i} \approx 100 \mathrm{MPa}$ is in satisfactory agreement with the literature data and confirms the fact that the supersaturation of ferrite of the pearlitic colony with carbon atoms does not affect the strength of steel after thermomechanical treatment.

The difference between the established value $k_{y} \approx 32 \mathrm{MPa} \cdot \mathrm{mm}^{0.5}$ and the values known from the literature $\left(20-22 \mathrm{MPa} \cdot \mathrm{mm}^{0.5}\right)$ for the major part of carbon and low-alloy steels with ferritic and pearlitic structures is more pronounced $[3,4]$. The value of $k_{y}$ can be elevated by the internal stresses caused by phase hardening as the temperature of the onset of pearlite transformation decreases [4]. This is confirmed by the results of $\mathrm{X}$-ray phase diffraction analysis. As the cooling rate of the rim of railway wheel increases from 2 to $9^{\circ} \mathrm{C} / \mathrm{sec}$, the width of the X-ray line (220) increases from 14.8 to $18.7 \mathrm{mrad}$, which confirms the formation of internal stresses caused by the phase hardening of ferrite in the pearlitic colony. Thus, the dependences of the strength characteristics of hot-deformed carbon steel on the cooling rate are determined by the state of interphase boundaries and the internal stresses caused by phase hardening in the course of pearlite reaction.

\section{CONCLUSIONS}

As the cooling rate of the rims of solid railway wheels increases from 2 to $9^{\circ} \mathrm{C} / \mathrm{sec}$ after its hot rolling, the supersaturation of the ferrite of pearlitic colony with carbon atoms is practically absent. The growth of the strength characteristics of wheel steel is determined by the internal stresses caused by phase hardening and the state of interphase boundaries of the pearlitic colonies.

\section{REFERENCES}

1. A. I. Babachenko, A. V. Knysh, A. A. Kononenko, et al., "Kinetics of the decomposition of supercooled austenite of steel for railway wheels under the conditions of continuous cooling," in: Building. Materials Science, Machine Building lin Russian], Issue 73, Pridneprovskaya Gos. Akad. Stroitel'stva Arkhitektury, Dnepropetrovsk (2014), pp. 65-69.

2. I. O. Vakulenko, Structural Analysis in Materials Science [in Ukrainian], Izd. Makovets'kyi Yu. V., Dnipropetrovs'k (2010). 
3. V. N. Gridnev, V. G. Gavrilyuk, and Yu. Ya. Meshkov, Strength and Plasticity of Cold-Deformed Steels [in Russian], Naukova Dumka, Kiev (1974).

4. I. A. Vakulenko and V. I. Bol'shakov, Structural Morphology and Strain Hardening of Steels [in Russian], Izd. Makovetskii Yu. V., Dnepropetrovsk (2008).

5. B. W. Crist and G. V. Smith, "Comparison of the Hall-Petch parameters of zone-refined iron determined by the grain size and extrapolation methods," Acta Met., 15, No. 5, 809-816 (1967).

6. A. R. Rosenfield, "The significance of $\sigma_{i}$ the friction stress contribution to the yield point of b.c.c. metals." J. Inst. Met.. 91 , $104-117(1962-1963)$. 


\title{
Ge Springer Link
}

\section{Influence of Cooling Rate on the Strength of the Rims of Railway Wheel}

\author{
Materials Science
}

May 2016, Volume 51, Issue 6, pp 839-842

I. O. Vakulenko

Article

First Online: 30 August 2016

DOI (Digital Object Identifier): 10.1007/s11003-016-9910-8

\section{Cite this article as:}

Vakulenko, I.O. Mater Sci (2016) 51: 839. doi:10.1007/s11003-016-9910-8

Views

It is shown that the intense cooling (with rates of $2-9^{\circ} \mathrm{C} / \mathrm{sec}$ ) of wheel rims after their hot rolling in a rolling mill increases the yield limit and the ultimate strength of the metal. It is also established that, in the absence of supersaturation of the solid solution with carbon atoms in the course of this kind of cooling, the mechanical properties of carbon steel are determined solely by the internal stresses caused by the phase hardening of ferrite in pearlite and the state of ferrite-cementite boundaries.

\section{Keywords}

wheel steel cooling rate pearlite ferrite strength dislocation

Translated from Fizyko-Khimichna Mekhanika Materialiv, Vol. 51, No. 6, pp. 80-82, November-December, 2015.

\section{References}

1. A. I. Babachenko, A. V. Knysh, A. A. Kononenko, et al., "Kineties of the decomposition of supercooled austenite of steel for railway wheels under the conditions of continuous cooling," in: Building, Materials Science, Machine Building [in Russian], Issue 73, Pridneprovskaya Gos. Akad. Stroitel'stva Arkhitektury, Dnepropetrovsk (2014), pp. 65-69.

2. 2. I. O. Vakulenko, Structural Analysis in Materials Science [in Ukrainian], Izd. Makovets'kyi Yu. V., Dnipropetrovs'k (2010). 